\title{
Marine Protected Areas (MPAs) Special Feature: Editorial
}

\author{
Andy Thorpe $\cdot$ Pierre Failler $\cdot$ J. Maarten Bavinck
}

Received: 28 January 2011/Accepted: 28 February 2011/Published online: 20 March 2011

(C) Springer Science+Business Media, LLC 2011

\begin{abstract}
The number of MPAs has increased sharply, from just 118 in 1970 to well over 6,300 today. This growth in numbers has also been accompanied by a voluminous growth in the academic literature on the theme, with writers employing ecologic, economic and governance lenses (or a combination thereof) to both support the case for MPA creation, and to evaluate just how successfully (or not) existing MPAs match up to their promises. Research suggests effective management of such protected areas is vital if desired outcomes are to be achieved within the allotted time period. This Special Feature on MPAs therefore seeks to address two key questions derived from the management effectiveness framework of Hockings and others (2000), namely: 'How appropriate are the management systems and processes in place?' and 'Were the desired Objectives achieved-and if so, why?' Fourteen articles, drawing on different disciplinary perspectives relating to MPA experiences from across the globe, offers insights into these questions by considering, inter alia, how: are MPA sites selected?; is 'buy-in' to the process from the various stakeholders achieved?; are these stakeholder's views reflected in the management systems that evolve?, and what monitoring and evaluation mechanisms
\end{abstract}

\footnotetext{
A. Thorpe $(\bowtie)$

Department of Economics, University of Portsmouth, Richmond Building, Portland Street, Portsmouth PO1 3DE, UK

e-mail: Andy.Thorpe@port.ac.uk

P. Failler

CEMARE, University of Portsmouth, Richmond Building,

Portland Street, Portsmouth PO1 3DE, UK

J. M. Bavinck

MARE, Universiteit van Amsterdam, Nieuwe Prinsengracht 130, Rm G2.05, Amsterdam 1018 VZ, The Netherlands
}

are in place? Bringing these perspectives and approaches together through the medium of this Special Feature is thus intended to further our understanding of the different issues that may confront both planners and managers of Marine Protected Areas.

Keywords Marine Protected Area - Customary rights . Coastal management - Stakeholder evaluation . Governability · Marine conservation · Management effectiveness

In a recent article in the Proceedings of the Academy of National Sciences, Pollnac and others (2010) highlighted that marine reserves are one of the 'key management measures' that can be used to mitigate the pervasive and strong anthropogenic influence on marine ecosystems. Nevertheless, as the same authors went on to report:

Marine reserves vary considerably in design, maintenance, and performance, in part because they are at the interface of complex social and ecological linkages. Social, economic, cultural and political conditions can have profound influences on the ways that societies organize to use and manage resources, including the development, placement, and implementation of nature reserves (p. 18262).

This is certainly true in a protected area universe that dates back to the designation of the San Juan County/ Cyprus Island Marine Biological Preserve (US) in 1923, and presently encompasses more than 5,000 reserves extending from the tiny Canadian MPA located at Echo Bay Provincial Park ( 0.4 hectares) to the extensive Phoenix Islands (off Kiribati) Protected Area which extends across 41 million hectares of sea and coastal ecosystem (UNEP 
2009). It is not just size or age that is important. MPAs also differ in terms of the marine ecosystems they seek to protect, the rationale for their formation (i.e., overfishing, to prevent the deleterious effects of developments in the adjoining coastal zone etc.) their objectives (i.e., fisheries or conservation-or a combination of the two; multiple-use area or no-take zone etc.), and how they impact on local community resource governance mechanisms. Moreover, as Field and others (2006) signal too, MPA creation has implications for conventional fisheries management systems as it 'can complicate the population-based paradigm of most fisheries stock assessments (p. 284).' MPA management, by definition then, is of critical importance-but no easy task.

Recognition of this prompted the World Wide Fund for Nature, in conjunction with the World Conservation Union (IUCN) World Commission on Protected Areas-Marine, to develop the MPA Management Effectiveness Initiative (MEI) in 2000. The Initiative resulted in the publication of How is Your MPA Doing? A Guidebook of Natural and Social Indicators for Evaluating Marine Protected Area Management Effectiveness (Pomeroy and others 2004) to 'better help MPA managers and practitioners better achieve the goals and objectives for which their MPA was created' (p. ix). While emphasizing that monitoring and evaluation were integral elements of an adaptive management process and there was a need to be more systematic in seeking to create a set of best MPA management practices, the manual also stressed there could be no 'one-stop shop' for policymakers and managers intent on creating and/or operating an MPA. Instead, it was imperative to also take on board the findings of other emerging work on the planning, design and implementation of MPAs (c.f: Agardy 1995; Salm and others 2000; Hockings and others 2000; Alder and others 2002), melding these analytic insights with local contextual materials to advance our understanding of how MPAs might be ever more effectively established/ managed.

This premise was central to the MPA Workpackage (developed by ourselves, the editors of this Special Feature) of an EU funded project entitled Ecosystems, Societies, Consilience and the Precautionary Principle: Development of an Assessment Method of the Societal Cost for Best Fishing Practices and Efficient Public Policies - ECOST (full details of the project and its outputs, funded under INCO-DEV Priority A.2.2. Reconciling Multiple Demands on Coastal Zones of the Sixth Framework Programme, can be found at: http://www.ird.fr/ecostproject/doku.php). In seeking to identify the criteria for comparing the societal cost of protected and unprotected areas and the likely impact of new modes of access regulation across four geographic regions and ecosystem types, we encountered a number of interesting articles on MPAs in the
Environmental Management journal (c.f. Lynch and others 2004; Beger and others 2004; Perera and de Vos 2007).

This prompted the idea of putting together a Special Feature on MPAs, a Special Feature that would not only draw upon papers produced within the ECOST project, but would embrace other research that dealt with various MPA aspects from a management perspective (whether it be identifying flaws in the Brazilian national system of MPAs, selecting potential MPA sites in Holland, understanding MPA governance in South Africa, or evaluating the effectiveness of management systems in coral reef MPAs). Moreover while such papers would draw from both different disciplines and geographic regions, the common thread that would link each and every article was management. This idea, along with a first draft listing of potential papers, was put to the Editor-in-Chief of Environmental Management-Virginia H. Dale-and following her acceptance, the project began. Since that time, papers have dropped out, others have been added, but the underlying principle remains the same: all of the fourteen articles contained in the following pages must, from whatever region or discipline they are drawn, in some way contribute to the MPA management debate.

While it is undeniable from the above discussion (and following papers) that MPA management is a complex task, two fundamental questions (derived from the management effectiveness framework of Hockings and others 2000) relating to MPA process and MPA outcomes can nevertheless be postulated which transcend considerations of region (in which the MPA is geographically sited) or rationale (for its creation). First: How appropriate are the management systems and processes in place (whether this be with regard to the creation of an MPA - as in the case of the Pearl Cays MPA in Nicaragua-or the subsequent operation of the MPA - as in the case of the Gulf of Mannar National Park and Biosphere Reserve in India)? Second: Were the desired objectives achieved - and, if so, why?. Pollnac (this issue), for example, stresses that MPA 'success' in the Visayas in the Philippines is predicated upon a series of factors, not least of which is the cohesion of the local community entities involved in the management of these areas.

The Special Feature is thus intended to provide further insights into these two questions, and is organised in three parts. The first part, consisting of three papers, surveys the MPA literature, and examines how global goals [targets] and a more anthropocentric approach to spatial planning might be accommodated within MPA management processes. The first paper, by Louisa Wood, proposes extending the SMART concept (specific, measurable, achievable, realistic and time-bound) deployed in climate data and global plant conservation management-among others-to assess the 2012 global marine protection targets 
laid out in the 2002 World Summit on Sustainable Development, the 2003 Seventh World Parks Congress and the Convention on Biological Diversity (CBD, Decision VIII/15). While expressing doubt as to whether the specific targets can be attained within the identified time window, like Gaines and others (2010), she does discern broader and growing political support for the notion of global marine reserve networks. While Claudet and Guidetti (2010) consider it timely to consider options to improve the evaluation of ecological effects of MPAs, the paper by Louise Teh and Lydia Teh in this volume argues in favour of also including more human dimensions in marine spatial management so as to ensure biological conservation targets are not prioritised over socio-economic considerations. A fuzzy logic framework which explicitly captures the social aspects of marine resource use via the Protected Area Suitability Index (PASI) is thus proposed (and thence applied) as a tool to help support managerial decisionmaking in the MPA arena. The final paper in this section, by Andy Thorpe and others, develops an analytic framework to gauge the foci (whether it be Biologic/Ecologic, Economic/Social, or Governance/Management) of policy documents and published scientific work on MPAs. The application of the resultant BEG framework to a sample of scientific articles published over the last fifteen years, while confirming the pre-eminence of biologic/ecologic research on the theme, nevertheless also uncovered evidence in the texts surveyed of a growing awareness of the importance of governance/management issues-the texts in the succeeding parts of this Special Feature being chosen so as to contribute further to this steadily accumulating literature.

The second section of this Special Feature, which is subdivided on a regional basis, pulls together a series of papers that address a range of management issues-extending from the creation to the evaluation of MPAs (while we considered organising the section on the basis of the lifecycle stages of an MPA, the regional ordering ultimately won out as we felt it best highlighted the issues-as identified by the authors of the papers-of particular interest from a regional perspective). The creation of marine reserves is often controversial (Smith and others 2010), a statement corroborated by Gianluca Ferrera and others who use MPA formation in Senegal as a vehicle for illustrating the complex interactions between international institutions and national actors. The research reveals a 'topdown' approach dominated, with MPAs established at the behest of international institutions by a supportive Presidency in the early part of the last decade. This triggered conflicts at both national and local level, with the process of MPA creation and MPA implementation becoming mired in issues of bureaucratic politics and personal gain. Merle Sowman and others also consider MPA identification and governance in South Africa has been dominated by a 'top-down' - and natural science based-paradigm that has 'hardly changed over the last half century.' Field research in two coastal fishing communities highlights the impact of, and conflicts emanating from, this traditional [in the South African context] paradigmatic approach, an approach which the authors argue undermines efforts to achieve conservation and fisheries management objectives. While MPA success is viewed as being critically dependent on addressing the root causes of resource decline and incorporating social factors into MPA identification, planning and management, the authors conclude that persuading ecologists, fisheries scientists and managers to embrace these factors remains a huge challenge in South Africa.

While there has been much research into MPAs and their effectiveness in the Philippines (c.f: Pollnac and others 2001; Samoilys and others 2007; Weeks and others 2009), the paper included by Richard Pollnac in this Special Feature seeks to 'tease out' the factors which underpin the success of community based MPA performance in the Visayas-and the importance of these factors in efforts to 'scale-up' the local MPA network. While (village) population size was found to resonate adversely upon the biological indicators (coral health, species diversity, top predators observed) employed in the study, it also impacted upon a communities ability to manage local resources, to abide by the rules of the MPA, and to develop features expected of a well-functioning MPA (management committees and management plans, monitoring programmes, physical delineation of the MPA etc.). Caution is thus urged by Pollnac in scaling-up, as larger networks will only function if the composite entities (villages or municipalities) are not only already functioning well, but are also effectively coordinated. While Pollnac casts an eye to extending MPA networks, the paper by Maarten Bavinck and Vivek Vriddagiri chooses to delve more deeply into one particular Indian MPA - the Gulf of Mannar National Park and Biosphere Reserve-in order to uncover the complexity of conflicts that have emerged and plague management decision-making there. Using a legal pluralism approach they urge authorities to not ignore wider social systems and structure when seeking to 'embed' MPAs into local environments, and concede that the varying wellbeing aspirations of the affected population will require the development of 'governance partnerships' if conflicts are to be minimised.

The Americas are represented by papers drawn from North, Central and South America respectively. Nadine Heck and others focus upon stakeholder perceptions of MPA effectiveness and, by extension, their willingness to participate in monitoring activities at the Pacific Rim National Park Reserve in Canada. The respondents in their study felt effectiveness was best assessed by a mix of diverse stakeholder groups and government agencies, 
rather than the Park authorities (as currently occurs), so as to offer greater credibility to the results obtained-and thereby encourage greater 'buy-in' by the affected parties and communities. Stakeholder involvement is also viewed as critical in the paper by Clarence Gonzalez and Svein Jentoft in the case of the Pearl Cays in Nicaragua, although here the emphasis is on involvement in MPA creation rather than MPA evaluation. Although the initial rationale for converting the Cays into an MPA was clearly conservation-based, this legally required local community assent. This proved to be a 'hard sell' as the communities saw the process as an opportunity to regain ownership and control of the Cays. Whether a 'win-win' solution can be found is still unclear, but given the widespread belief (c.f. Kelleher and others 1995) that community support is a pre-requisite for a successful MPA, much work remains to be done to ensure the MPA project is not lost before it is formally launched. The paper by Leopoldo Gerhardinger and others provides an overview of MPA process in the biggest country in Latin America. Their thesis-that marine protected 'dramas' (institutional weaknesses in the country's marine conservation agency ICMBio, overly bureaucratic management and administrative systems, a lack of funding, and a disconnect between MPA policy and its delivery, among others) are endemic across the 62 MPAs in the Brazilian National System of MPAs-is accompanied by a call for both micro- (ie: localised audits of ICMBio's activities) and macro- (state championing of MPAs and the National System) measures to remedy these managerial and institutional shortcomings.

Peter Mackleworth and others examine the interaction between marine conservation and EU accession in the context of the Adriatic coast of Croatia. Intents to harmonise national conservation legislation with the EU Habitats Directive, resolve contested maritime borders with Slovenia, and reconcile national demands for an expanded fishing fleet with the EU Common Fisheries Policy has thrown into sharp relief the issue of sovereign rights. Accession will see the Adriatic fall into 'common EU maritime space', with the authors fearing greater exploitation and reduced maritime sustainability is likely in the long term. Elaine van Haastrecht and Hilde Toonen also employ a national lens, focusing upon how the Netherlands is intending to live up to its obligations in the area of marine conservation following the country's ratification of the CBD. Zeroing in on the science-policy interactions that formed part of the process of designating the first MPA in the Dutch part of the North Sea, they show there is no 'winwin scenario' with site selection ultimately being a "balancing act between ecological, socio-economic and political interests, in which scientific and policy guiding procedures blend with ad-hoc political decision-making, and with expert judgement in cases where data is lacking."
Oceania is represented by a paper by Melissa NurseyBray on the Great Barrier Reef [GBR] MPA. While the GBR provides worthy lessons of how large-scale MPA networks can contribute to integrated, adaptive management processes (McCook and others 2010), Nursey-Bray chooses to focus on how local management scenarios are influenced by indigenous social contexts. The precariousness of many indigenous livelihoods, she contends, makes it imperative to promote biodiversity processes and practices that protect and enhance these livelihoods and nurtures cultural traditions, a task that demands the integration of a number of different knowledge domains (indigenous, modernist, conservationist etc.) if management strategies are to be effective-and successful-within the GBR MPA. The third and final section of the Special Feature contains one paper (by Venetia Hargreaves-Allen and others), and returns to the global, asking whether Coral Reef MPAs are producing conservation and socio-economic improvements. Using a sample of 78 MPAs drawn from across the globe she detects some success in meeting certain 'fundamental' managerial performance goals (increasing coral cover, reduced conflict) despite many of these MPAs being small, underfunded, and at threat from outside forces. This leads her to postulate that with greater resources and access to 'best available science' MPA performance could further be enhanced-a desirable scenario given the vulnerability of reef ecosystems to ongoing climatic change.

Each of these fourteen papers provide a series of insights into the fundamental questions highlighted earlier. In the case of the first of these two questions: How Appropriate are the Management Systems and Processes in Place? A key stumbling block, as Sowman and colleagues (this volume) recognise, is identifying — and agreeing — upon the objectives for the area under consideration for protected status in the first place. This involves trust-trust between, among others, management practitioners, communities located in or adjacent to the area, and those who currently (and might in the future) access the resources therein. Nursey-Bray in her paper shows, for example, how legal process (notably the 1992 'Mabo decision') has, by clarifying questions relating to indigenous rights, proved incidental in providing a framework within which indigenous peoples and fisheries management experts have worked together to create innovative policy and effective on-theground management regimes in Australia's aquatic space. If agreement on the underlying rationale for a MPA can be reached, then the chances of implementing a management system that addresses ecologic and/or economic desires and reflects local needs and sensitivities is enhanced. In the case of the Croatian Adriatic, for example, as Mackelworth (this volume) highlights, there is a very real danger that national conservation initiatives will be compromised by 
EU accession and the greater exploitation of the coastal shelf following incorporation of the Adriatic Coast into the 'common EU maritime space.'

In the case of the second: Were the desired Objectives achieved? Objectives, as Coulthard and others show, can be framed in a number of domains (ecological-biological, socio-economic, governance) and, moreover, differences may well exist among stakeholders regarding the appropriate evaluation strategy to be employed (see Heck and others). For this reason, as Chrisite (2004) notes, it is plausible that MPAs considered to be a conservation success-insofar as they have met narrowly defined biological goals-may be viewed as socio-economic 'failures' when social evaluation criteria are deployed. This is one of the reasons for Wood (this volume) proposing that global marine protection objectives are SMART targets, a methodology that could equally be oriented to objective-setting at the local level to ensure that ideological clashes regarding ecological and socio-economic value of different types of MPAs ... should not be allowed to fester and impede crucial conservation efforts' (Agardy and others 2003). The assessment of management performance against clearly defined, quantified (where necessary), and agreed objectives is imperative then if the ecosystem protection and biodiversity conservation arenas are not to continue lagging behind other policy fields in terms of effective evaluation (Ferraro and Pattanayak 2006).

It is thus hoped that this Special Feature will not only contribute to increased interest in MPAs as a policy tool which can complement existing fisheries management and marine conservation regimes but also, through the diversity of disciplinary and regional perspectives adopted, further underline that:

“... taking into account the many human dimensions of Marine Protected Areas (MPAs)—social, economic, cultural, and institutional-is critical to MPA success (Charles and Wilson 2009:6).

\section{References}

Agardy T (1995) The science of conservation in the coastal zone: new insights on how to design, implement, and monitor marine protected areas. IUCN Marine Conservation and Development Report, IUCN, Gland (Switzerland)

Agardy T, Bridgewater P, Crosby MP, Day J, Dayton PK, Kenchington R, Laffoley D, McConney P, Murray PA, Parks JE, Peau L (2003) Dangerous targets? Unresolved issues and ideological clashes around marine protected areas. Aquatic Conservation: Marine and Freshwater Ecosystems 13:353-367

Alder J, Zeller D, Pitcher TJ, Sumaila UR (2002) A method for evaluating marine protected area management. Coastal Management 30(2):121-131

Beger M, Harborne AR, Dacles TP, Solandt J-L, Ledesma GL (2004) A framework of lessons learned from community-based marine reserves and its effectiveness in guiding a new coastal management initiative in the Philippines. Environmental Management 34(6):786-801

Charles A, Wilson L (2009) Human dimensions of marine protected areas. ICES Journal of Marine Sciences 66(1):6-15

Chrisite P (2004) Marine protected areas as biological successes and social failures in Southeast Asia'. American Fisheries Society Symposium, Mimeo

Claudet J, Guidetti P (2010) Viewpoint: improving assessments of marine protected areas'. Aquatic Conservation: Marine and Freshwater Ecosystems 20:239-242

ECOST Project. http://www.ird.fr/ecostproject/doku.php. Accessed 1 Jan 2011

Ferraro PJ, Pattanayak SK (2006) Money for nothing? A call for empirical evaluation of biodiversity conservation investments. PLoS Biology 4(4):0482-0488

Field JC, Punt AE, Methot RD, Thomson CJ (2006) Does MPA mean "major problem for assessments?" Considering the consequences of place-based management systems. Fish and Fisheries 7:284-302

Gaines SD, White C, Carr MHm, Palumbi SR (2010) Designing marine reserve networks for both conservation and fisheries management. Proceedings of the Academy of National Sciences of the United States of America 107(43):18286-18293

Hockings M, Stolton S, Dudley N (2000) Evaluating effectiveness: a framework for assessing the management of protected areas. IUCN, Gland (Switzerland)

Kelleher G, Bleakley C, Wells SM (eds) (1995) A global representative system of marine protected areas. World Bank/IUCN, Washington DC

Lynch TP, Wilkinson E, Melling L, Hamilton R, Macready A, Feary $S$ (2004) Conflict and impact of divers and anglers in a marine park. Environmental Management 33(2):196-211

McCook LJ, Ayling T, Cappo M, Choat JH, Evans RD, De Freitas DM, Heupel M, Hughes TP, Jones GP, Mapstone B, Marsh H, Mills M, Molloy FJ, Pitcher CR, Pressey RL, Russ GR, Sutton S, Sweatman H, Tobin R, Wachenfield DR, Williamson DH (2010) Adaptive management of the Great Barrier Reef: a globally significant demonstration of the benefits of networks of marine reserves. Proceedings of the National Academy of Sciences of the United States of America 107(43):18278-18285

Perera N, de Vos A (2007) Marine protected areas in Sri Lanka: a review. Environmental Management 40(5):727-738

Pollnac R, Crawford BR, Gorospe MLG (2001) Discovering factors that influence the success of community-based marine protected areas in the Visayas, Philippines. Ocean \& Coastal Management 44:683-710

Pollnac R, Christie P, Cinner JE, Dalton T, Daw TM, Forrester GE, Graham NAJ, McClanahan TR (2010) Marine reserves as linked social-ecological systems. Proceedings of the National Academy of Sciences of the United States of America 107(43): $18262-18265$

Pomeroy RS, Parks JE, Watson LM (2004) How is your MPA doing? A guidebook of natural and social indicators for evaluating marine protected area management effectiveness. IUCN, Gland (Switzerland)

Salm RV, Clark JR, Siirila E (2000) Marine and coastal protected areas: a guide for planners and managers. IUCN, Washington DC

Samoilys MA, Martin-Smith KM, Giles BG, Cabrera B, Anticamara JA, Brunio EO, Vincent ACJ (2007) Effectiveness of five small Philippines' coral reef reserves for fish populations depends on site-specific factors, particularly enforcement history. Biological Conservation 136:584-601

Smith MD, Lynham J, Sanchirico JN, Wilson JA (2010) Political economy of marine reserves: understanding the role of 
opportunity costs. Proceedings of the National Academy of Sciences of the United States 107(43):18300-18305

UNEP (2009) UNEP launches new online system to view and study the World's Marine protected areas. http://www.unep.org/ Documents.Multilingual/Default.asp?DocumentID $=589 \&$ Article $\mathrm{ID}=6212 \& \mathrm{l}=\mathrm{en} \& \mathrm{t}=$ long. Accessed 31 Dec 2010
Weeks R, Russ GR, Alcala AC, White AT (2009) Effectiveness of marine protected areas in the philippines for biodiversity conservation. Conservation Biology 24(2):531040 